\title{
CANNIBALISM IN CULTURED EURASIAN PERCH, PERCA FLUVIATILIS (ACTINOPTERYGII: PERCIFORMES: PERCIDAE)-IMPLICATION OF MATERNAL INFLUENCE, KINSHIP, AND SEX RATIO OF PROGENIES
}

\author{
Jarosław KRÓL ${ }^{1 *}$, Nicolas DAUCHOT ${ }^{2}$, Syaghalirwa N.M. MANDIKI ${ }^{3}$, \\ Pierre VAN CUTSEM ${ }^{2}$, and Patrick KESTEMONT ${ }^{3}$ \\ ${ }^{1}$ Department of Ichthyology, University of Warmia and Mazury in Olsztyn, Poland \\ ${ }^{2}$ Unité de Recherche en Biologie Cellulaire Végétale, University of Namur, Belgium \\ ${ }^{3}$ Unité de Recherche en Biologie Environnementale et Evolutive, University of Namur, Belgium
}

\begin{abstract}
Król J., Dauchot N., Mandiki S.N.M., Van Cutsem P., Kestemont P. 2015. Cannibalism in cultured Eurasian perch, Perca fluviatilis (Actinopterygii: Perciformes: Percidae)-Implication of maternal influence, kinship, and sex ratio of progenies. Acta Ichthyol. Piscat. 45 (1): 65-73.
\end{abstract}

Background. Intra cohort cannibalism is one of the main factors that affects the growth and survival of cultured fishes, especially in the larval and juvenile stages. Cannibalism is mainly influenced by extrinsic factors, but intrinsic effects cannot be excluded. As regards the family Percidae, all-female rearing can be advantageous for the fish growth, but does this solution have some impact on cannibalism? The main objective of this study was to investigate potential differences in cannibalism rate and its relation to further growth and survival between mixed-sex and all-female Eurasian perch, Perca fluviatilis Linnaeus, 1758, larvae reared in full-siblings and halfsiblings groups. The additional purpose of this study was to determine whether there was some maternal influence on the cannibalism-survival-growth dynamics in cultured Eurasian perch larvae.

Materials and methods. Cannibalism, survival, and growth were studied in mixed-sex and all-female progenies of Eurasian perch larvae. Ten-day old larvae (body weight of $20 \mathrm{mg}$ ) originating from the crosses of four parents (two females: f1 and f2; one male: ma; and one neomale: $\mathrm{mc}$ ) were reared over 77 days at $22^{\circ} \mathrm{C}$ under the light regime of $16: 8$ (light : dark) in replicated groups consisting of mixed-sex full siblings (f1ma, f2ma), all-female full siblings (f1mc, f2mc), or mixed-sex half-siblings (f1ma $+\mathrm{f} 2 \mathrm{ma}$ ) and all-female groups (f1mc $+\mathrm{f} 2 \mathrm{mc}$ ).

Results. At the end of the experiment, there was no sexual growth dimorphism and no sex-biased cannibalism. Neither the effect of sibling versus half-sibling groups, nor effects of normal progeny versus all-female population on survival and cannibalism rate were significant. By contrast, maternal effects on cannibalism were observed, chiefly as regards type I cannibalism (partial and tail-first ingestion), and they impacted on survival, as mortality from other causes (complete cannibalism or others) was independent from maternal origin.

Conclusion. There is no particular disadvantage of rearing monosex female progenies in term of cannibalism and survival, whereas this culture-management solution is prone to produce long-term advantages for the perch growth, owing to the faster growth of female fish.

Keywords: cannibalism, percids, larvae, juvenile, all female, dam effect

\section{INTRODUCTION}

Sexual growth dimorphism is not rare among teleost fishes. Controlling the phenotypic sex of farmed fish is potentially one of the most promising strategies for improving production and profitability in aquaculture $\mathrm{A}$ (Strüssmann and Nakamura 2002). In some species, the use of monosex can provide additional benefits such as reducing aggressive interactions between conspecifics or controlling spontaneous reproduction in captivity (Beardmore et al. 2001). In case of Eurasian perch, Perca fluviatilis Linnaeus, 1758, because of the faster growth and later maturation of females, the production of all-female stocks may have potential applications in culture management of this species (Kestemont and Mélard 2000). All-female perch progenies could be obtained by using hormonally reversed XX neomale breeders (Rougeot et al. 2002). However, it has not been examined whether the benefits of using all-female progenies were accompanied with similar dynamics of cannibalism-survival-growth.

\footnotetext{
${ }^{*}$ Correspondence: Dr Jarosław Król, Katedra Ichtiologii, Uniwersytet Warmińsko Mazurski w Olsztynie, ul. Warszawska 117A, 10-718 Olsztyn, Poland, phone/fax: +48 89 523 37 54, e-mail(JK): krolas@uwm.edu.pl, (ND): nicolas.dauchot@fundp.ac.be, (SNMM): robert.mandiki@fundp.ac.be, (PC): pierre.vancutsem@fundp.ac.be, (PK): patrick.kestemont@fundp.ac.be.
} 
The growth dynamics of a cohort of fish larvae is frequently affected by multiple interactive and non-interactive factors such as environment and population structure, respectively (Kestemont et al. 2003). High size variation can facilitate the emergence of cannibalism (Baras and Jobling 2002). Cannibalistic behaviour also has some effect on size heterogeneity, which can increase or decrease, depending on prey size preference, alternative food resources and proportions of fish exercising cannibalism (Hecht and Appelbaum 1988, Baras and Jobling 2002). Under culture conditions, intra-cohort cannibalism is one of the main factors that affects the growth and survival of fishes, especially during the early life stages of carnivorous species (Smith and Reay 1991, Hecht and Pienaar 1993, Baras and Jobling 2002, Król et. al. 2014). In percid fish, intra-cohort cannibalism can induce losses exceeding 50\% of the stock during the first 2 weeks of rearing (Baras et al. 2003, Kestemont et al. 2003, Babiak et al. 2004, Hamza et al. 2007). Previous studies indicated that increasing stocking density did not impair the growth of Eurasian perch larvae, whereas it significantly decreased the frequency of cannibalism. By contrast, in young juveniles cannibalism was enhanced under high stocking densities (Mélard et al. 1996, Baras et al. 2003, Kestemont et al. 2003) and the growth was slower (Babiak et al. 2004). The dynamics of growth, size dispersal, and cannibalism in fishes can be complex: a study in perch reported that the size dispersal could have some unexpected positive effects, as it prevents the emergence of new cannibals, thereby reducing the overall impact of cannibalism (Mandiki et al. 2007).

There are two hypotheses behind the occurrence of cannibalistic behaviour in cultured fish. First, a size difference between a potential prey and a cannibal can induce cannibalistic attack. Second, some fish are simply "natural born killers" with a greater propensity to exercise cannibalism than others (Baras and Jobling 2002). There is increasing evidence that the latter hypothesis is not prevalent (Baras and Lucas 2010, Baras et al. 2014) and cannibalism is increasingly regarded as an alternative feeding strategy, under the influence of environmental factors (Hecht and Pienaar 1993, Svenning and Borgstrøm 2005). However, interactions between genetic and environmental factors cannot be excluded, as intrinsic effects on the variability of growth (as the main cause of cannibalism) during the larval or juvenile stages have been showed in several species (Saillant et al. 2001, Butts and Litvak 2007, Ottesen and Babiak 2007, Núñez et al. 2011). Furthermore fish hybridization, domestication, or strains selection for culture may enhance cannibalism in cultured species (Thibault 1974, van Damme et al. 1989, Hecht and Piennar 1993, Baras and Jobling 2002). Intra-cohort cannibalism may also be sex biased in fast growing species with sexual growth dimorphism taking place during first weeks after hatching (Baras 1999b). However, the influence of the earlier mentioned effects on intra-cohort cannibalism in Eurasian perch has never been examined.

Therefore, the main objective of this study was to determine potential differences in the rates of cannibalism and their relation with growth and survival in mixed-sex and all-female Eurasian perch larvae reared in full sibling and half-sibling contexts. An additional objective of the present study was to evaluate maternal influences on cannibalism-survival-growth relations in cultured Eurasian perch larvae.

\section{MATERIALS AND METHODS}

Production of larvae. Two perch females: $f 1$ and $f 2$ and one perch male ma were captured from the Meuse River near Namur (Belgium). A perch neomale mc was taken from a sex-reversed line produced at the Aquaculture Training and Research Center in Tihange (University of Liege, Belgium). Four basic progenies of perch larvae were produced, two mixed-sex progenies (f1ma, f2ma) and two all-female progenies (f1mc, f2mc). Egg ribbons from both females were fertilized by the dry method and were incubated in an indoor recirculating water system at $17^{\circ} \mathrm{C}$. Just before hatching, the ribbons were placed in $1000-\mathrm{L}$ tanks. The temperature was gradually increased to $20^{\circ} \mathrm{C}$ and dissolved oxygen was maintained to saturation $\left(9.5 \mathrm{mg} \cdot \mathrm{L}^{-1}\right)$ with aerators. Cannibalism in larvae can vary strongly between progenies, depending on the proportion of fish that are incapable to feed exogenously (for perch, Baras et al. 2003). In order to avoid this issue, larvae were kept in hatching tanks for the next 9 days before the start of the experiment, as fish incapable of feeding generally die within this interval at $20^{\circ} \mathrm{C}$. Larvae were fed, from 4 day post hatching, with Artemia nauplii (EG grade, INVE, Belgium) in slight excess, 6 times daily, from 0900 to $1800 \mathrm{~h}$.

Experimental design. On day 10 post hatching (before the emergence of cannibalism, considered as the day 0 of the experiment), six experimental treatments, consisting either of mixed-sex full siblings (f1ma, f2ma), all-female full siblings (f1mc, f2mc), mixed-sex half-siblings (f1ma + $\mathrm{f} 2 \mathrm{ma}$, equally), and all-female half-siblings (f1 mc $+\mathrm{f} 2 \mathrm{mc}$, equally) consisted of three replications for full siblings and two for half siblings (because of limited number of tanks in the recirculating system). Experimental groups were selected as to be able to test for the effect of sex (mixed-sex versus all-female), to test for the effect of kinship (full siblings versus half siblings) and finally to test for a possible dam effect (comparison between full sibs and within half sibs). Larvae were manually counted, assigned randomly to $30-\mathrm{L}$ tanks in an indoor recirculation water system. In each group, the stocking density was 50 larvae $\cdot \mathrm{L}^{-1}$. Just before the start of the experiment, 40 larvae from each experimental group were killed by using an overdose of an anaesthetic (tricaine methanesulfonate, MS-222, $200 \mathrm{mg} \cdot \mathrm{L}^{-1}$ ) and weighed individually (to the nearest $0.001 \mathrm{~g}$ ). The experiment lasted 77 days. Fish were fed exclusively Artemia nauplii for the first 11 days of the experiment. Then, they were gradually switched to dry food (Nippaï, Catvis, the Netherlands, $54 \%$ of protein). After 22 days, fish were fed exclusively dry food (Trouvit, France, $54 \%$ of protein) by hand 5 times daily, from 0900 to $1800 \mathrm{~h}$. Until day 22, the feeding was in 
slight excess the daily feeding level decreased from 100\% fish biomass on day 23 to $5 \%$ on day 76 . The light regime of was set as $16: 8$ (light : dark) and the water temperature was $22^{\circ} \mathrm{C}$, which is near optimal for perch larvae growth and survival (Jourdan et al. 2000). Water was UV treated, dissolved oxygen was maintained close to saturation, and nitrogenous compounds did not exceed 0.2 and $0.07 \mathrm{mg} \cdot \mathrm{L}^{-1}$ for $\mathrm{NH}_{4}^{+}$and $\mathrm{NO}_{2}^{-}$, respectively.

Data analysis. Dead fish were removed daily and were classified as truncated (caudal end damaged or tailed-off) or non-truncated: starving, intact, or having bitten abdomen or head. Truncated individuals were considered victims of incomplete (type I) cannibalism, as previously defined (Braband 1995, Baras et al. 2003). Traces of fish bites on the abdomen or head are typical secondary postmortem damages in cultured Eurasian perch, therefore individuals with such damages were not classified as victims of cannibalism. At the end of the experiment, all survivors were counted. Missing fish were considered victims of complete (type II) cannibalism. Mean fish body weight and size dispersal were obtained from the individual weighing of 50 fish in each tank. These fish were killed with an overdose of MS-222 and their gonads were examined for sex determination: perch males have two testes whereas females have a single ovary (Rougeot et al. 2002, Babiak et al. 2004). Fish sex was further verified with histological method in 10 fish from each group (gonads fixed in Bouin, 5- $\mu \mathrm{m}$ sections stained with haematoxylin and eosin, Pearse 1985). The serial cross sections were analyzed under the light microscope for the shape, size and type of germ cells present in gonads.

Coefficients of variation $(\mathrm{CV})$ in body weight [\%] were calculated for 0 and 77 days of experiment based on the formula:

$$
\mathrm{CV}=100 \cdot \mathrm{SD}_{W} \cdot W^{-1}
$$

where $W$ is average body weight and $\mathrm{SD}_{W}$ is standard deviation of body weight.

The overall specific growth rate $(\mathrm{SGR})\left[\% \cdot\right.$ day $\left.^{-1}\right]$ was also calculated based on the formula:

$$
\mathrm{SGR}=100\left(\operatorname{Ln} W_{2}-\operatorname{Ln} W_{1}\right) \cdot t^{-1}
$$

where $W_{1,2}$ are the initial and final average body weights [g] and $t$ is the time interval between the beginning and end of the experiment ( 77 days here).

Parentage assignment. The four parents were genetically characterized with five microsatellite markers, originally isolated from American yellow perch, Perca flavescens (Mitchill, 1814), and available from GenBank, where they are referred to as Pfla L1 (Af211826), Pfla L2 (Af211827), Pfla L4 (Af211829), Pfla L6 (Af211831), and Pfla L9 (Af211834). Primer pairs and cycling conditions were defined according to Leclerc et al. (2000). Briefly, perch nuclear DNA was isolated from caudal fin stored either in $96 \%$ ethanol at room temperature or as frozen tissue samples at $-20^{\circ} \mathrm{C}$ using DNAzol genomic DNA isolation reagent (Invitrogen, USA). Polymerase chain reactions were performed on an I-cycler (Biorad) in $25 \mu \mathrm{L}$ volume with 0.5 unit GoTaq polymerase (Promega) and $2.5 \mathrm{pM}$ of each primer. To allow fluorescent detection of the amplification products, one primer out of each pair was labelled with a Wellred dye D2, D3, or D4 (Proligo). Primer pairs were labelled with different colours to allow multiplexing of the detection. One $\mu \mathrm{L}$ out of each amplification product was diluted in $40 \mu \mathrm{L}$ deionized formamide and analyzed using fluorescent capillary electrophoresis device (Beckman Coulter CEQ8000 Genetic Analysis System). Alleles were manually scored. For identification of juvenile fish at the end of experiment, two primer pairs Pfla L2 and Pfla L9 sufficed for univocal discrimination between the female parents used here. Parentage assignment was determined in the half sibling groups $(35 \%$ and $32 \%$ of all survivors in $\mathrm{f} 1 \mathrm{ma}+\mathrm{f} 2 \mathrm{ma}$ and $\mathrm{f} 1 \mathrm{mc}+\mathrm{f} 2 \mathrm{mc}$, respectively).

Statistical analyses. Growth parameters, mortality rates (including cannibalism) and mean body weight were compared using one-way ANOVA. Normality of parameters distributions was tested by Kolmogorov-Smirnov test. The data expressed in percentages were Arcsin transformed prior to statistical analysis. Significance of differences between groups was estimated using a post hoc Duncan's multiple range test. For CV values, a non-parametric Kruskal-Wallis test was used. Observed proportions of half-siblings after microsatellite analysis were compared to an expected $1: 1$ ratio with chi-square test. Null hypotheses were rejected at $P<0.05$. Analyses were performed using Statistica software (StatSoft).

Ethical issues. The experiment has been carried out in accordance with regulations of the Animal Ethics Committee in Belgium.

\section{RESULTS}

Initial body weight $\left(W_{0}\right)$ did not differ among siblings stocks (Table 1). Over the entire experiment, body weight increased from $0.018 \mathrm{~g}$ (day 0) to more than $6 \mathrm{~g}$ (day 77). Final body weights $\left(W_{77}\right)$ and total specific growth rates (SGR) did not differ among experimental groups (Table 1). Identification of fish by microsatellite analysis did not reveal any significant differences between the final weights of half-siblings within mixed stocks. Likewise the final body weights of females and males in mixed-sex groups did not differ significantly either (Table 1). CV in weights almost doubled during the experiment but did not differ among all groups (Table 1).

Survival in full sibling groups ranged from $36 \%$ to $61 \%$ and varied significantly as a function of maternal parentage (Fig. 1), i.e., fish originating from female f 2 had higher survival rates than those from f1 (Fig. 1). A similar maternal influence on survival was found within halfsibling groups (f1ma $+\mathrm{f} 2 \mathrm{ma}$ and $\mathrm{f} 1 \mathrm{mc}+\mathrm{f} 2 \mathrm{mc})$ after parentage assignment (Fig. 2).

Mortalities due to other causes than cannibalism were not different among groups and not correlated with final survival (Figs. 3 and 4). Type I cannibalism was relatively high during the whole experiment, especially between the 5th and 6th week (Fig. 3). Neither effects of siblings versus half-siblings, nor effects of mixed sex progeny versus all female stocks on cannibalism and survival rates 
were found. The intensity of type I cannibalism among full siblings was higher $(P<0.05)$ in f1 groups $(27.2 \%-45.1 \%)$ than in $f 2$ groups $(6.6 \%-20.2 \%$, Fig. 4$)$. Type II cannibalism also differed among groups, but in contrast to the situation for type I cannibalism, it was significantly lower in mixed-sex groups from f1 (0.4\%) compared to $\mathrm{f} 2(12.3 \%)$. A similar though non-significant trend was observed in all-female stocks $(15.4 \%$ versus $25.4 \%$, for $\mathrm{f} 1$ and $\mathrm{f} 2$, respectively, Fig. 4). Mortality caused by both types of cannibalism (I and II) did not significantly differ among full sibling $(P<0.05)$, but slight higher values in $\mathrm{f1}$ groups $(42.3 \%-45.5 \%)$ than in $\mathrm{f} 2$ groups $(31.1 \%-32.6 \%)$ were observed. There were no clear-cut relations between both types of cannibalism, fish growth or size dispersal.

Sex ratios in mixed-sex groups never differed from $1: 1$. Gross morphological examination of the gonads confirmed that all fish from monosex groups were females. Histological sections of the gonads showed that ovaries of females from mixed-sex and all-female progenies did not differ one from another in the developmental stage and size. In both cases ovaries containing ovarian lamellae were filled up with previtellogenic oocytes (Fig. 5a, 5b). In male perch, seminal ampullae in testes were characterized by regular shape; they were filled up with cells representing developmental stages of early spermatogenesis and on some instances spermatids and spermatozoids (Fig. 5c).

\section{DISCUSSION}

In the presently reported study growth did not differ as a function of fish sex, group sex ratio, or degree of kinship (full versus half siblings). The absence of significant sexrelated effect on the growth of Eurasian perch is in agreement with previous studies on the American yellow perch (Malison et al. 1988) and the Eurasian perch (Babiak et al. 2004). Stejskal et al. (2009) found that the significance differences in body weight between all-female and mixedsex stocks of perch began at age 144 days, when fish were over $13 \mathrm{~g}$. The sexual growth dimorphism in perch probably appears markedly when sexual maturation reduces somatic growth. As showed by histological examination, both sexes of the perch at the end of the presently reported experiment were just at the beginning of gametogenesis.

Babiak et al. (2004) found that initial average size and size dispersal could affect the subsequent growth and survival of Eurasian perch larvae. However, it is not continuously, because initial size heterogeneity had no impact on further heterogeneity in juvenile stages in the Eurasian perch (Kestemont et al 2003). In the presently reported study, no significant influence of initial body weight and its $\mathrm{CV}$ on final weight or size heterogeneity were found. Some explanation may be that Babiak et al (2004) examined perch larvae with much broader ranges of $\mathrm{CV}$ values than this study, and this could be the reason why they found a marked effect of initial CV on growth and size heterogeneity.

Under culture conditions, cannibalism is one of the main factors which could drastically decrease the survival of the stock, especially in larvae and juveniles of fast growing predatory species like sea bass, Dicentrarchus labrax (Linnaeus, 1758) (see Katavić et al. 1989); vundu catfish, Heterobranchus longifilis Valenciennes, 1840 (see Baras 1999a); walleye, Sander vitreus (Mitchill, 1818)

Table 1

Body weight, size dispersal, and specific growth rate of Eurasian perch, Perca fluviatilis, reared in mixed-sex fullsibling groups, all-female full-sibling groups, mixed-sex half-sibling group, and all-female half-sibling group

\begin{tabular}{|c|c|c|c|c|c|c|c|}
\hline \multirow{3}{*}{$\begin{array}{l}\text { Experimental } \\
\text { group }\end{array}$} & \multicolumn{2}{|c|}{ Day 0} & \multicolumn{5}{|c|}{ Day 77} \\
\hline & \multirow{2}{*}{$W_{0}[\mathrm{~g}]$} & \multirow{2}{*}{$\mathrm{CV}_{0}[\%]$} & \multicolumn{3}{|c|}{$W_{77}[\mathrm{~g}]$} & \multirow{2}{*}{$\mathrm{CV}_{77}[\%]$} & \multirow{2}{*}{$\begin{array}{c}\text { SGR } \\
{\left[\% \cdot \text { day }^{-1}\right]}\end{array}$} \\
\hline & & & $q+\hat{o}$ & q & $\hat{0}$ & & \\
\hline flma & $0.022 \pm 0.008$ & 20.83 & $6.07 \pm 1.03$ & $6.21 \pm 0.93$ & $5.74 \pm 1.11$ & $45.8 \pm 2.9$ & $7.2 \pm 0.2$ \\
\hline $\mathrm{f} 2 \mathrm{ma}$ & $0.018 \pm 0.004$ & 22.22 & $5.92 \pm 0.42$ & $5.98 \pm 0.39$ & $5.81 \pm 0.51$ & $42.5 \pm 6.6$ & $7.5 \pm 0.1$ \\
\hline $\mathrm{flmc}$ & $0.019 \pm 0.006$ & 31.58 & $5.35 \pm 1.22$ & $5.35 \pm 1.22$ & - & $53.3 \pm 1.8$ & $7.3 \pm 0.3$ \\
\hline $\mathrm{f} 2 \mathrm{mc}$ & $0.019 \pm 0.005$ & 26.32 & $5.45 \pm 0.95$ & $5.45 \pm 0.95$ & - & $58.6 \pm 9.9$ & $7.3 \pm 0.2$ \\
\hline \multirow[t]{2}{*}{$\mathrm{f} 1 \mathrm{ma}+\mathrm{f} 2 \mathrm{ma}$} & $0.021 \pm 0.005$ & 23.81 & $5.13 \pm 0.32$ & $5.43 \pm 0.29(\mathrm{fl})$ & $5.13 \pm 0.31(\mathrm{f} 1)$ & $45.7 \pm 5.5$ & $7.1 \pm 0.3$ \\
\hline & & & & $5.21 \pm 0.22(\mathrm{f} 2)$ & $5.06 \pm 0.33(\mathrm{f} 2)$ & & \\
\hline \multirow[t]{2}{*}{$\mathrm{f} 1 \mathrm{mc}+\mathrm{f} 2 \mathrm{mc}$} & $0.019 \pm 0.006$ & 31.32 & $5.87 \pm 0.45$ & $5.95 \pm 0.28(\mathrm{f} 1)$ & - & $47.3 \pm 0.9$ & $7.3 \pm 0.1$ \\
\hline & & & & $5.84 \pm 0.36(\mathrm{f} 2)$ & & & \\
\hline
\end{tabular}

f1 $\mathrm{ma}$ and $\mathrm{f} 2 \mathrm{ma}=$ mixed-sex full-sibling groups, f1 $\mathrm{mc}$ and $\mathrm{f} 2 \mathrm{mc}=$ all-female full-sibling groups, f1ma $+\mathrm{f} 2 \mathrm{ma}=\mathrm{mixed}-\mathrm{sex}$ half-sibling group f1 mc $+\mathrm{f} 2 \mathrm{mc}=$ all-female half-sibling group; $W_{0}=$ body weight of fish at the beginning of the experiment, $W_{77}$ = body weight of fish at the end of the experiment, $\mathrm{CV}_{0}=$ coefficient of variation of body weight at the beginning of the experiment, $\mathrm{CV}_{77}=$ coefficient of variation of body weight at the end of the experiment, $\mathrm{SGR}=$ overall specific growth rate; $\mathrm{f} 1$ or $\mathrm{f} 2=$ body weight of male or female originating from female 1 or female 2 , respectively within half-sibling stocks (f1ma $+\mathrm{f} 2 \mathrm{ma}$ or $\mathrm{f} 1 \mathrm{mc}+\mathrm{f} 2 \mathrm{mc}$ ); Fish age at the beginning of the experiment (Day 0 ) was 10 days after hatching; Values are the mean \pm standard deviation of three (full siblings) or two (half-siblings) replications, issued from two female parents (f1 and f2), and one XY male (ma) or one XX neomale $(\mathrm{mc})$; Values did not differ significantly $(P>0.05)$. 
(see Loadman et al. 1986); or European catfish, Silurus glanis Linnaeus, 1758 (see Król et al. 2014). In previous studies on Eurasian perch larvae, the losses to type II cannibalism largely outnumbered those to type I cannibalism (Braband 1995, Mélard et al. 1996, Baras et al. 2003, Babiak et al. 2004). The presently reported study confirmed that cannibalism is the most important factor affecting survival in Eurasian perch larviculture. However, in contrast to the aforementioned studies, the average mortality caused by type I cannibalism was high-

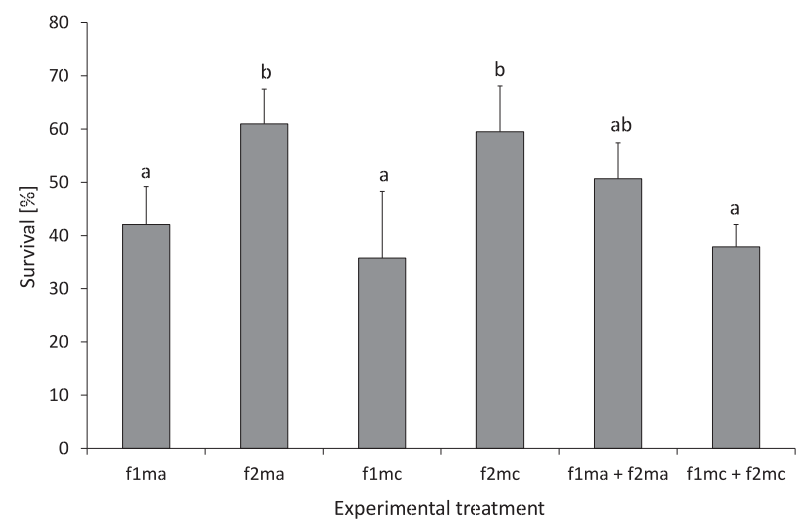

Fig. 1. Survival of Eurasian perch, Perca fluviatilis, reared as mixed-sex full-siblings (f1ma and f2ma), allfemale full-siblings (f1mc and $\mathrm{f} 2 \mathrm{mc}$ ), mixed-sex halfsiblings (f1ma + f2ma), and all-female half-siblings $(\mathrm{f} 1 \mathrm{mc}+\mathrm{f} 2 \mathrm{mc})$; Bars and whiskers are mean \pm standard deviation values of three (full-siblings) or two replicates (half-siblings); Bars marked with different letters differ at $P<0.05$

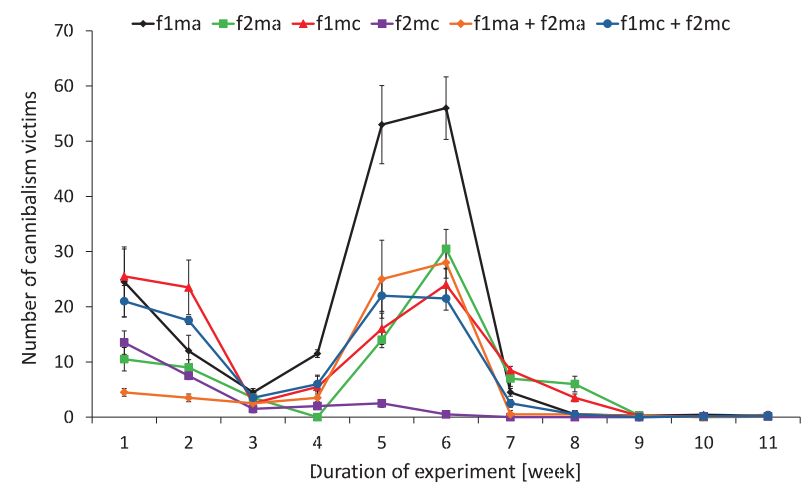

Fig. 3. Weekly dynamics of mortalities caused by type I cannibalism in the experimental groups of Eurasian perch, Perca fluviatilis, reared as mixed-sex full-siblings (f1ma and $\mathrm{f} 2 \mathrm{ma}$ ), all-female full-siblings (f1mc and $\mathrm{f} 2 \mathrm{mc}$ ), mixed-sex half-siblings (f1ma + f2ma), and all-female half-siblings (f1mc $+\mathrm{f} 2 \mathrm{mc}$ ); Symbols and whiskers are mean \pm standard deviation values of three (full-siblings) or two replicates (half-siblings) er than type II. In Eurasian perch larvae, type I cannibalism usually commences as soon as on day 10 (Baras et al. 2003) or on days 16 through 30 (Babiak et al. 2004) post hatching, depending on culture conditions. After its appearance, type I cannibalism is rapidly replaced by type II within a week. In the presently reported study, mortalities caused by type I cannibalism were recorded from the beginning to the week 7 of experiment corresponding to day 60 post-hatching. The fact is that aforementioned studies started at hatching (Mélard et al. 1996, Baras et

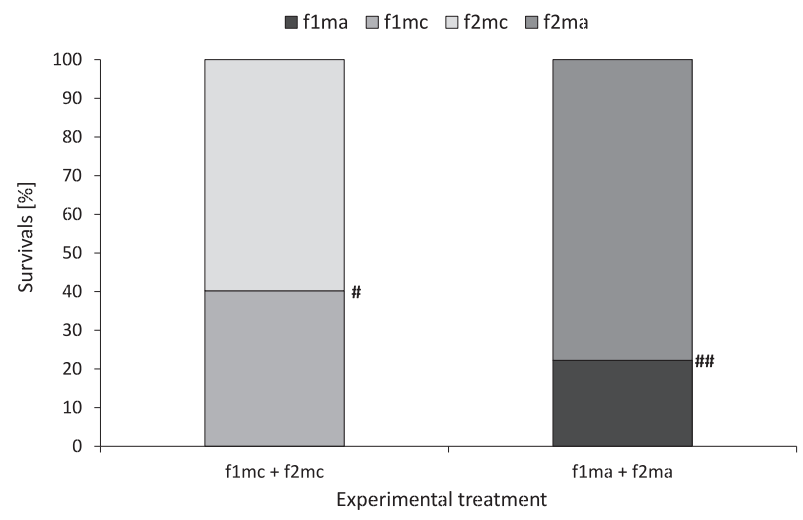

Fig. 2. Parental assignment of Eurasian perch, Perca fluviatilis, survivors in mixed half-siblings (f1ma $+\mathrm{f} 2 \mathrm{ma})$ and all-female half-siblings (f1mc $+\mathrm{f} 2 \mathrm{mc}$ ), as determined by microsatellite analysis; Observed proportions were compared with expected $1: 1$ proportions with chi-square tests: ${ }^{\#} \chi^{2}=3.84, P=0.049,{ }^{\# \#} \chi^{2}=30.91$, $P<0.00001$; One hundred fish were analyzed for both experimental situations ( $35 \%$ and $32 \%$ of all survivors from $\mathrm{f} 1 \mathrm{ma}+\mathrm{f} 2 \mathrm{ma}$ and $\mathrm{f} 1 \mathrm{mc}+\mathrm{f} 2 \mathrm{mc}$, respectively)

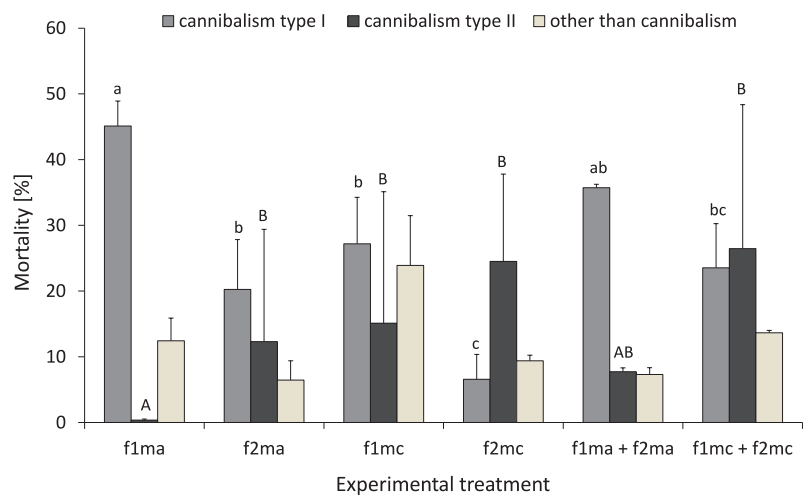

Fig. 4. Respective contributions of incomplete (type I) and complete (type II) cannibalism, and mortality from other causes in the experimental groups of Eurasian perch, Perca fluviatilis, reared as mixed-sex full-siblings (f1ma and f2ma), all-female full-siblings (f1mc and $\mathrm{f} 2 \mathrm{mc}$ ), mixed-sex half-siblings (f1ma + $\mathrm{f} 2 \mathrm{ma}$ ) and all-female half-siblings (f1mc $+\mathrm{f} 2 \mathrm{mc}$ ); Bars and whiskers are mean \pm standard deviation values of three (full-siblings) or two replicates (half-siblings); Bars marked with different letters (lower case for type I, upper case for type II) differ at $P<0.05$ 
al. 2003), whereas our study started with much larger fish (about $20 \mathrm{mg}$ ) and only fish having successfully achieved the transition to exogenous feeding were used. This context is prone to limit growth heterogeneity, thereby limiting the possibility of complete cannibalism, and just leaving the door to incomplete cannibalism. It is also possible that the refinement of feeding schedules over the past 10 years contributed to limited growth heterogeneity, thereby limiting the occurrence of type II cannibalism. This largely accounts for the difference between the respective contributions of type I and type II cannibalism here in comparison to other studies. Nevertheless, type I cannibalism was particularly intense from the time of complete weaning of fish on formulated feed (22 days post hatching here). This supports the statement by Hecht and Pienaar (1993) that weaning is a critical period in the culture of piscivorous species and could therefore influence the occurrence cannibalistic behaviours. Whatever the exact causes behind the late emergence or peaking of type I cannibalism here, it comes out that in every experimental situation, incomplete cannibalism discontinued after about 50 days and had not been observed thereafter.

Intra-cohort cannibalism may be sex biased in species with growth dimorphism among gender during early ontogeny, e.g., vundu catfish (Baras 1999b), but this was not observed in the presently reported study, presumably as the growth rates of male and female perch juveniles were still similar at the end of the experiment. This study further revealed that the sex ratio had no influence on the rate of cannibalism, which was similar in mixed-sex and all-female stocks. As regards the possible influence of kinship, the present study provided evidence that the rates of cannibalism in half-sibling groups were intermediate between those of full-sibling groups. A similar observation was made by Baras and d'Almeida (2001) in the sharptooth catfish, Clarias gariepinus (Burchell, 1822).

One of the objectives of the presently reported study was to examine whether there was some maternal influence on cannibalism-survival-growth dynamics in cultured Eurasian perch larvae. In groups containing fish originating from $\mathrm{f} 2$, the type I cannibalism was lower than in groups containing fish originating from $\mathrm{fl}$ while type II was slightly higher in $\mathrm{f} 2$ than $\mathrm{fl}$. In fish species, the "natural born killers" hypothesis suggesting that some fish have a greater propensity to exert cannibalism than others has been supported by few studies (Thibault 1974, Hecht and Pienaar 1993). By hybridization experiments, it was demonstrated that koi carp (a morph of Cyprinus carpio Linnaeus, 1758) are more cannibalistic than other strains of common morphs of carp as a result from domestication process and selection for the coloured morph by breeders (van Damme et al. 1989). Such evidence, however, has not been found in other fish species. Indeed, in Arctic charr, Salvelinus alpinus (Linnaeus, 1758), the environmental conditions and the size heterogeneity have a higher impact on cannibalistic behaviour than the genotype (Svenning and Borgstrøm 2005). Likewise, recent studies on the individual performance of siblings in fish species with strong cannibalistic tendencies suggest that cannibals are lottery winners rather than natural born killers (Baras and Lucas 2010, Baras et al. 2014, Król et al. 2014). Therefore, within a particular progeny, cannibalism can presumably be regarded as an alternative feeding strategy, directly or indirectly influenced by environmental factors rather than any genetic components.
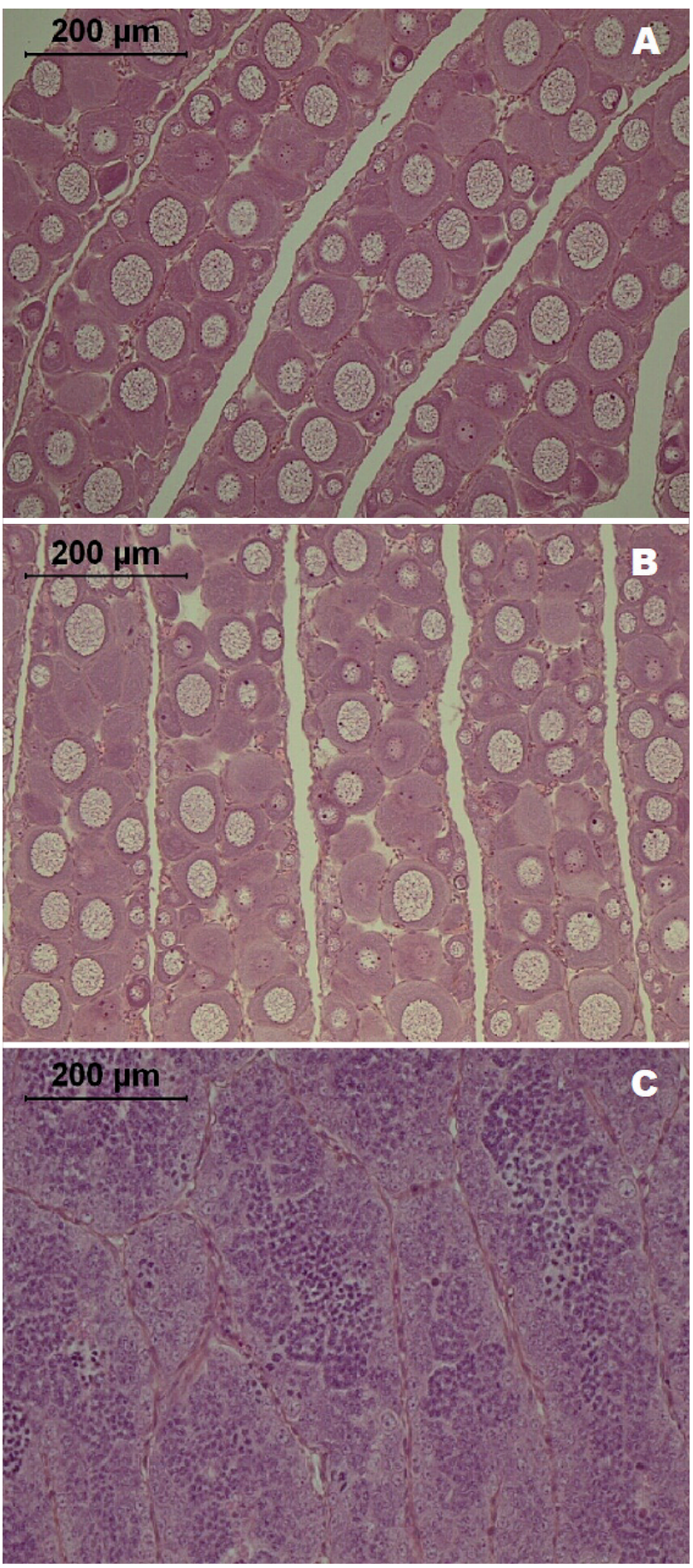

Fig. 5. Histological cross-sections of gonads of Eurasian perch, Perca fluviatilis, at the end of experiment: A, ovaries from a female fish originating from all-female progeny; $\mathbf{B}$, ovaries from a female fish originating from a mixed-sex progeny; $\mathbf{C}$, testis from a male fish originating from a mixed-sex progeny 
Nevertheless, this interpretation does not imply that genetic components have no effect on cannibalism (Hecht and Pienaar 1993, Svenning and Borgstrøm 2005). Dam effect on survival during embryonic development is common among fish and often related to egg size or yolk composition (Rana 1985, Marteinsdottir and Steinarsson 1998). In rainbow trout, Oncorhynchus mykiss (Walbaum, 1792), the influence of female parent on the survival of embryos is considerable while the paternal effect is minor, usually due to a very limited number of males (Herbinger et al. 1995, Nagler et al. 2000). Similar results were reported in European sea bass where survival during incubation and hatching is mainly influenced by the female parent, with negligible paternal contribution (Saillant et al. 2001). On the other hand, a major effect of both parents was found on the differential survival of larvae of the European sea bass (Garcia de Leon et al. 1998) and Atlantic halibut, Hippoglossus hippoglossus (Linnaeus, 1758) (see Jackson et al. 2003). Likewise paternal and maternal effects were observed on hatching success, yolk utilization efficiency and growth in the Amazonian catfish, Pseudoplatystoma punctifer (Castelnau, 1855) (see Núñez et al. 2011). Maternal effect on progeny mortality via larval size variability was demonstrated in Eurasian perch (Babiak et al. 2004) and sharptooth catfish (Adamek et al. 2011). In the presently reported study, although the initial body weight of Eurasian perch larvae did not differ between stocks, some maternal influence on survival was found both in full-sibling groups and in halfsibling groups, as confirmed by microsatellite analysis.

Summing up, in this study no major differences in the cannibalism, the growth, and the survival were observed between mixed-sex and all-female Eurasian perch larvae. This is an encouraging result as regards the possibility of producing fast-growing, all-female progenies that can be a key to the success of the Eurasian perch aquaculture. Some maternal influence, regardless of initial larval size variability, on cannibalism-survival relation was reported here. We are aware that only four parents were used in this study. Further experiments with larger sample size are necessary to test whether cannibalism in Eurasian perch under culture conditions is governed by parenthood (i.e., male or female and their interaction). It is possible, that maternal influence can be much more determinant in very young larvae, the early growth of which depends intimately on the size and quality of the yolk, but this particular issue requires additional research.

\section{ACKNOWLEDGEMENTS}

This study was funded by the Belgian National Funds for Science (FNRS, contract no. 2.4568.00). First author was a post-doctoral grant holder from FNRS. The authors are grateful to A. Evrard and N. Ndonide (University of Namur) for their technical assistance.

\section{REFERENCES}

Adamek J., Kamler E., Epler P. 2011. Uniform maternal age/size and light restrictions mitigate cannibalism in Clarias gariepinus larvae and juveniles reared under production-like controlled conditions. Aquacultural Engineering 45 (1): 13-19.

DOI: 10.1016/j.aquaeng.2011.05.001

Babiak I., Mandiki S.N.M., Ratsinjomanana K., Kestemont P. 2004. Initial weight and its variation in post-larval Eurasian perch affect quantitative characteristics of juvenile cohorts under controlled conditions. Aquaculture 243 (1-4): 263-276. DOI: $10.1016 /$ j.aquaculture.2003.12.010

Baras E. 1999a. Sibling cannibalism among juvenile vundu under controlled conditions. I. Cannibalistic behaviour, prey selection and prey size selectivity. Journal of Fish Biology 54 (1): 82-105.

DOI: $10.1111 / j .1095-8649.1999 . t b 00614 . x$

Baras E. 1999b. Functional implications of early sexual growth dimorphism in vundu. Journal of Fish Biology 54 (1): 119-124. DOI: 10.1111/j.1095-8649.1999.tb00616.x

Baras E., d'Almeida A.F. 2001. Size heterogeneity prevails over kinship in shaping cannibalism among larvae of sharptooth catfish Clarias gariepinus. Aquatic Living Resources 14 (4): 251-256.

DOI: $10.1016 / \mathrm{S} 0990-7440(01) 01118-4$

Baras E., Hafsaridewi R., Slembrouck J., Priyadi A., Moreau Y., Pouyaud L. 2014. Do cannibalistic fish possess an intrinsic higher growth capacity than others? A case study in the Asian redtail catfish Hemibagrus nemurus (Valenciennes, 1840). Aquaculture Research 45 (1): 68-79. DOI: $10.1111 /$ j.1365-2109.2012.03205.x

Baras E., Jobling M. 2002. Dynamics of intracohort cannibalism in cultured fish. Aquaculture Research 33 (7): 461-479. DOI: $10.1046 / j .1365-2109.2002 .00732 . x$

Baras E., Kestemont P., Mélard C. 2003. Effect of stocking density on the dynamics of cannibalism in sibling larvae of Perca fluviatilis under controlled conditions. Aquaculture 219 (1-4): 241-255.

DOI: $10.1016 / \mathrm{S} 0044-8486(02) 00349-6$

Baras E., Lucas M.C. 2010. Individual growth trajectories of sibling Brycon moorei raised in isolation since egg stage, and their relationship with aggressive behaviour. Journal of Fish Biology 77 (4): 985-997. DOI: $10.1111 / \mathrm{j} .1095-8649.2010 .02740 . \mathrm{x}$

Beardmore J.A., Mair G.C., Lewis R.I. 2001. Monosex male production in finfish as exemplified by tilapia: applications, problems, and prospects. Aquaculture 197 (1-4): 283-301. DOI: $10.1016 / \mathrm{S} 0044-8486(01) 00590-7$

Braband A. 1995. Intra-cohort cannibalism among larval stages of perch (Perca fluviatilis). Ecology of Freshwater Fish 4 (2): 70-76. DOI: $10.1111 /$ j.1600-0633.1995.tb00119.x

Butts I.A.E., Litvak M.K. 2007. Parental and stock effects on larval growth and survival to metamorphosis in winter flounder (Pseudopleuronectes americanus). Aquaculture 269 (1-4): 339-348.

DOI: 10.1016/j.aquaculture.2007.04.012

Garcia de Leon F.J., Canonne M., Quillet E., Bonhomme F., Chatain B. 1998. The application of microsatellite markers to breeding programmes in the sea bass, Dicentrarchus labrax. Aquaculture 159 (3-4): 303-316.

DOI: $10.1016 / \mathrm{S} 0044-8486(97) 00188-9$ 
Hamza N., Mhetli M., Kestemont P. 2007. Effects of weaning age and diets on ontogeny of digestive activities and structures of pikeperch (Sander lucioperca) larvae. Fish Physiology and Biochemistry 33 (2): 121-133.

DOI: $10.1007 / \mathrm{s} 10695-006-9123-4$

Hecht T., Appelbaum S. 1988. Observations on intraspecific aggression and coeval sibling cannibalism by larval and juvenile Clarias gariepinus (Clariidae: Pisces) under controlled conditions. Journal of Zoology 214 (1): 21-44.

DOI: 10.1111/j.1469-7998.1988.tb04984.x

Hecht T., Pienaar A.G. 1993. A review of cannibalism and its implications in fish larviculture. Journal of the World Aquaculture Society 24 (2): 246-261.

DOI: $10.1111 / j .1749-7345.1993 . t b 00014 . x$

Herbinger C.M., Doyle R.W., Pitman E.R., Paquet D., Mesa K.A., Morris D.B., Wright J.M., Cook D. 1995. DNA fingerprint based analysis of paternal and maternal effects on offspring growth and survival in communally reared rainbow trout. Aquaculture 137 (1-4): 245-256.

DOI: 10.1016/0044-8486(95)01109-9

Jackson T.R., Martin-Robichaud D.J., Reith M.E. 2003. Application of DNA markers to the management of Atlantic halibut (Hippoglossus hippoglossus) broodstock. Aquaculture 220 (1-4): 245-259.

DOI: $10.1016 / \mathrm{S} 0044-8486(02) 00622-1$

Jourdan S., Fontaine P., Boujard T., Vandeloise E., Gardeur J.N., Anthouard M., Kestemont P. 2000. Influence of daylength on growth, heterogeneity, gonad development, sexual steroids and thyroid levels, and $\mathrm{N}$ and P budgets in Perca fluviatilis. Aquaculture 186 (3-4): 253-265.

DOI: 10.1016/S0044-8486(99)00357-9

Katavić I., Jug-Dujaković J., Glamuzina B. 1989. Cannibalism as a factor affecting the survival of intensively cultured sea bass (Dicentrarchus labrax) fingerlings. Aquaculture 77 (2-3): 135-143.

DOI: 10.1016/0044-8486(89)90197-X

Król J., Flisiak W., Urbanowicz P., Ulikowski D. 2014. Growth, cannibalism, and survival relations in larvae of European catfish, Silurus glanis (Actinopterygii: Siluriformes: Siluridae) — atempts to mitigate sibling cannibalism. Acta Ichthyologica et Piscatoria 44 (3): 191-199. DOI: 10.3750/AIP2014.44.3.03

Kestemont P., Jourdan S., Houbart M., Mélard C., Paspatis M., Fontaine P., Cuvier A., Kentouri M., Baras E. 2003. Size heterogeneity, cannibalism and competition in cultured predatory fish larvae: biotic and abiotic influences. Aquaculture 227 (1-4): 333-356.

DOI: $10.1016 / \mathrm{S} 0044-8486(03) 00513-1$

Kestemont P., Mélard C. 2000. Aquaculture. Pp. 191-224. In: Craig J.F. (ed.) Percid fishes - systematics, ecology and exploitation. Fish and Aquatic Resources Series 3. Blackwell Science, Oxford, UK.

Leclerc D., Wirth T., Bernatchez L. 2000. Isolation and characterization of microsatelitte loci in yellow perch (Perca flavescens), and cross-species amplification within the family Percidae. Molecular Ecology 9 (7): 995-997.

DOI: 10.1046/j.1365-294x.2000.00939-3.x
Loadman N.L., Moodie G.E.E., Mathias J.A. 1986. Significance of cannibalism in larval walleye (Stizostedion vitreum). Canadian Journal of Fisheries and Aquatic Sciences 43 (3): 613-618.

DOI: $10.1139 / \mathrm{f} 86-073$

Malison J.A., Kayes T.B., Wentworth B.C., Amundson C.H. 1988. Growth and feeding responses of male versus female yellow perch (Perca flavescens) treated with estradiol-17 $\beta$. Canadian Journal of Fisheries and Aquatic Science 45 (11): 1942-1948.

DOI: $10.1139 / \mathrm{f} 88-226$

Mandiki S.N.M., Babiak I., Krol J., Rasolo J.F.R., Kestemont P. 2007. How initial predator-prey ratio affects intra-cohort cannibalism and growth in Eurasian perch Perca fluviatis L larvae and juveniles under controlled conditions. Aquaculture 268 (1-4): 149-155.

DOI: $10.1016 / j$.aquaculture.2007.04.036

Marteinsdottir G., Steinarsson A. 1998. Maternal influence on the size and viability of Iceland cod Gadus morhua eggs and larvae. Journal of Fish Biology 52 (6): 1241-1258.

DOI: $10.1111 / j .1095-8649.1998 . t b 00969 . x$

Mélard C., Baras E., Mary L., Kestemont P. 1996. Relationships between stocking density, growth, cannibalism and survival rate in intensively cultured larvae and juveniles of perch (Perca fluviatilis). Annales Zoologici Fennici 33 (3-4): 643-651.

Nagler J.J., Parsons J.E., Cloud J.G. 2000. Single pair mating indicates maternal effects on embryo survival in rainbow trout, Oncorhynchus mykiss. Aquaculture 184 (1-2): 177-183. DOI: 10.1016/S0044-8486(99)00309-9

Nuñez J., Castro D., Fernández C., Dugué R., Chu-Koo F., Duponchelle F., García C., Renno J.-F. 2011. Hatching rate and larval growth variations in Pseudoplatystoma punctifer: maternal and paternal effects. Aquaculture Research 42 (6): 764-775.

DOI: $10.1111 / \mathrm{j} .1365-2109.2011 .02803 . \mathrm{x}$

Ottesen O.H., Babiak I. 2007. Parental effects on fertilization and hatching success and development of Atlantic halibut (Hippoglossus hippoglossus L.) embryos and larvae. Theriogenology 68 (9): 1219-1227. DOI: $10.1016 /$ j.theriogenology.2007.08.015

Pearse A.G.E. 1985. Histochemistry. Theoretical and applied. Vol. 2. Analytic technology. 4th edn. Churchill Livingstone, Edinburgh. London, Melbourne and New York.

Rana K.J. 1985. Influence of egg size on the growth, onset of feeding, point-of-no-return, and survival of unfed Oreochromis mossambicus fry. Aquaculture 46 (2): 119-131. DOI: 10.1016/0044-8486(85)90196-6

Rougeot C., Jacobs B., Kestemont P., Mélard C. 2002. Sex control and sex determinism study in Eurasian perch, Perca fluviatilis, by use of hormonally sex-reversed male breeders. Aquaculture 211 (1-4): 81-89.

DOI: $10.1016 / \mathrm{S} 0044-8486(01) 00893-6$

Saillant E., Chatain B., Fostier A., Przybyla C., Fauvel C. 2001. Parental influence on early development in the European sea bass. Journal of Fish Biology 58 (6): 1585-1600.

DOI: $10.1111 / j .1095-8649.2001 . t b 02314 . x$ 
Smith C., Reay P. 1991. Cannibalism of teleost fish. Review in Fish Biology and Fisheries 1 (1): 41-64.

DOI: $10.1007 / \mathrm{BF} 00042661$

Stejskal V., Kouřil J., Musil J., Hamáčkova J., Policar T. 2009. Growth pattern of all-female perch (Perca fluviatilis L.) juveniles-Is monosex perch culture beneficial? Journal of Applied Ichthyology 25 (4): 432-437.

DOI: $10.1111 / j .1439-0426.2009 .01253 . x$

Strüssmann C.A., Nakamura M. 2002. Morphology, endocrinology, and environmental modulation of gonadal sex differentiation in teleost fishes. Fish Physiology and Biochemistry 26 (1): 13-29.

DOI: $10.1023 / \mathrm{A}: 1023343023556$

Svenning M.-A., Borgstrom R. 2005. Cannibalism in Arctic charr: Do all individuals have the same propensity to be can- nibals? Journal of Fish Biology 66 (4): 957-965.

DOI: $10.1111 / \mathrm{j} .0022-1112.2005 .00646 . \mathrm{x}$

Thibault R.E. 1974. Genetics of cannibalism in a viviparous fish and its relationship to population density. Nature 251 (5471): 138-140.

DOI: $10.1038 / 251138 \mathrm{a} 0$

van Damme P., Appelbaum S., Hecht T. 1989. Sibling cannibalism in Koi carp, Cyprinus carpio L., larvae and juveniles reared under controlled conditions. Journal of Fish Biology 34 (6): $855-863$.

DOI: $10.1111 / \mathrm{j} .1095-8649.1989 . t b 03369 . x$

Received: 18 October 2014

Accepted: 27 January 2015

Published electronically: 31 March 2015 